\title{
Valuasi Ekonomi Hutan Kota Serang
}

\author{
Anis Masyruroh ${ }^{7}$, Iroh Rahmawati ${ }^{2}$ \\ 1,2Universitas Banten Jaya, Serang \\ *surel: anismasyruroh@unbaja.ac.id
}

\begin{abstract}
Benefits and existence of urban forests as green open spaces are often ignored by the community. Economic valuation becomes a tool to calculate the loss of benefit value from the urban forest ecosystem if it is not maintained and preserved. This study aims to (1) calculate the total economic value of urban forests; (2) know the community's perception of the physical and non-physical conditions of the forest in Serang City. This study used a survei method with economic valuation techniques and a Likert scale in order to determine the perceptions of visitors about the physical and non-physical conditions of the urban forest. The results showed that the total economic value of urban forest per year was $R p .3,650,118,222$, -. The results of community perception showed that, Serang city forest visitors do not agree that this area has good physical and non-physical conditions. In physical and non-physical condition, Serang city forest is quite low.
\end{abstract}

\section{Keywords:}

Economic valuation, city forest, forest economic value, willingness to pay, direct use value,

Submitted: January 2021

Reviewed: January 2021

Published: February 2021

\section{INTISARI}

Manfaat dan keberadaan dari hutan kota sebagai ruang terbuka hijau sering kali diabaikan oleh masyarakat. Valuasi ekonomi menjadi suatu alat untuk menghitung kehilangan nilai manfaat dari ekosistem hutan kota jika tidak dijaga dan dipelihara kelestariannya. Penelitian ini bertujuan untuk (1) menghitung nilai ekonomi total hutan kota; (2) mengetahui persepsi masyarakat terhadap kondisi fisik dan non-fisik hutan kota Serang. Penelitian ini menggunakan metode survei dengan teknik valuasi ekonomi dan skala likert untuk mengetahui persepsi pengunjung mengenai kondisi fisik dan non-fisik hutan kota. Hasil penelitian menunjukkan bahwa Nilai Ekonomi Total Hutan Kota per tahun sebesar Rp.3.650.1 18.222,00 Hasil Pengolahan data persepsi masyarakat, pengunjung hutan kota Serang kurang setuju bahwa kawasan ini memiliki kondisi fisik dan nonfisik yang baik. Secara kondisi fisik dan non-fisik hutan kota Serang tergolong cukup rendah.

\section{Kata Kunci:}

Valuasi Ekonomi, Hutan Kota, Nilai Ekonomi hutan, Nilai Guna Langsung Nilai kesediaan membayar

Diterima: Januari 2021

Direview: Januari 2021

Dipublikasi: Februari 2021

(C)2021 Anis Masyruroh, Iroh Rahmawati. Published by Institute for Research and Community Services Universitas Muhammadiyah Palangkaraya. This is Open Access article under the CC-BY-SA License (http://creativecommons.org/licenses/by-sa/4.0/). DOl: https://doi.org/10.33084/mitl.v6il.2017

\section{PENDAHULUAN}

Kota adalah suatu permukaan wilayah administrasi pemerintahan dengan berbagai jenis aktivitas manusia berupa ekonomi, sosial budaya yang pada akhirnya membentuk sentralisasi penduduk [1]. Kota Serang, merupakan ibu kota Provinsi Banten yang keberadaannya dikelilingi oleh berbagai 
kabupaten maupun kota. Kota Serang, saat ini menjadi pusat aktivitas, dan pusat migrasi dari kabupaten yang berada di sekitarnya sehingga mengakibatkan terjadinya pertumbuhan penduduk sangat pesat. Hal ini tentu berpengaruh terhadap pembangunan, baik pembangunan fisik maupun pembangunan non fisik. Pembangunan industri misalnya, pada tahun 2014 meningkat sebanyak 1.144 unit dibandingkan tahun 2013 yang hanya berkisar 1.000 unit, kemudian peningkatan pembangunan perumahan pada tahun 2015 telah menggunakan wilayah seluas $89,95 \mathrm{~km}^{2}$ [2].

Dua komponen ini secara langsung dan tidak langsung akan mengubah tatanan kota secara fisik seperti adanya alih fungsi lahan dan mengubah ekosistem perkotaan. Hal ini mengakibatkan ruang yang tersedia akan mengalami peningkatan beban lingkungan, karena Kota Serang hanya memiliki luas wilayah sekitar $266,74 \mathrm{~km}^{2}$ [2].

Kota Serang pada tahun 2016 memiliki hutan kota sekitar 1,4 hektar [2]. menurut hasil pengamatan saat ini kondisi hutan kota serang tidak terawat dengan baik, sehingga keberadaannya kurang memberikan fungsi ekologis terhadap lingkungan hidup. Hal ini diperlukan adaya sebuah terobosan konsep pembangunan hutan kota, agar keberadaanya dapat memberikan fungsi yang maksimal terhadap perbaikan kualitas lingkungan hidup.

Menurut UU No.26 tahun 2007 tentang Penataan Ruang, dimana luas RTH seharusnya minimal $30 \%$ dari luas suatu kota. Salah satu komponen ruang terbuka hijau yang harus dipertahankan bahkan ditingkatkan luasnya adalah hutan kota. Hutan kota merupakan kawasan veget asi berkayu yang luas serta jarak tanamnya terbuka bagi umum, mudah dijangkau oleh penduduk kota, dan dapat memenuhi fungsi perlindungan dan regulatifnya, seperti kerelatifan tanah, tata air, penangkal polusi udara, kebisingan dan lain-lain [3].

Valuasi ekonomi merupakan upaya untuk memberikan nilai kuantitatif terhadap barang dan jasa yang dihasilkan oleh sumberdaya alam dan lingkungan, baik atas dasar nilai pasar (market value) maupun nilai non-pasar (non market value) [4]. Valuasi ekonomi sumberdaya merupakan suatu alat ekonomi (economic tool) yang menggunakan teknik penilaian tertentu untuk mengestimasi nilai vang dari barang dan jasa yang dihasilkan oleh sumberdaya alam dan lingkungan. Pemahaman tentang konsep valuasi ekonomi memungkinkan para pengambil kebijakan dapat menentukan penggunaan sumberdaya alam dan lingkungan yang efektif dan efisien. Hal ini disebabkan aplikasi valuasi ekonomi menunjukkan hubungan antara konservasi sumber daya alam dengan pembangunan ekonomi [4].

Terdapat beberapa peranan hutan kota dalam kehidupan perkotaan, diantaranya pelestarian plasma nutfah. Hutan kota dapat dijadikan sebagai tempat koleksi keanekaragaman hayati yang tersebar diseluruh wilayah tanah air kita. Kawasan hutan kota dapat dipandang sebagai areal 
pelestarian di luar kawasan konservasi, karena pada areal ini dapat dilestarikan flora dan fauna secara eksitu [1].

Penilaian ekonomi terhadap sumberdaya alam dan lingkungan perlu dilakukan untuk menggambarkan pentingnya hutan kota dalam mengurangi kerugian lingkungan akibat pembangunan kota. Penelitian ini bertujuan (1) menghitung nilai ekonomi total hutan kota (nilai guna langsung, nilai guna tidak langsung, nilai pilihan, nilai warisan, dan nilai keberadaan) (2) mengetahui persepsi masyarakat terhadap kondisi fisik (aspek air, udara dan ekologis) dan non fisik (kesejukan, dan kenyamanan) hutan kota.

\section{METODOLOGI}

Metode analisis yang digunakan dalam penelitian ini adalah statistik deskriptif dengan mendeskripsikan data yang telah terkumpul. Analisis difokuskan pada hasil pengamatan atau observasi lapangan dan persepsi dari masyarakat mengenai kondisi fisik dan nonfisik hutan kota. Lokasi penelitian hutan kota Serang, merupakan ruang terbuka hijau yang berlokasi di Kelurahan Banjarsari, Kecamatan Cipocok Jaya, Kota Serang. Luas kawasan hutan kota Serang adalah 1,4 hektar ${ }^{[1]}$ dan secara geografis terletak pada 608'59"S $106^{0} 11 ' 31$ "E.

\section{Prosedur Penelitian}

Data yang digunakan dalam penelitian ini meliputi data primer dan data sekunder. Data primer hasil survei lapangan dilakukan dengan cara menyebarkan kuesioner kepada responden yang mengunjungi hutan kota yaitu sebanyak 100 responden. Data sekunder adalah data yang bersumber dari pihak berwenang dalam pengelolaan hutan kota didapatkan dengan wawancara di Kantor Bappeda, Dinas Kehutanan, Badan Lingkungan Hidup Daerah (DLHD), Badan Pusat Statistik (BPS) Kota Serang. Data sekunder pada penelitian ini menggunakan data Bapeda kota Serang tahun 2019 sampai dengan 2020.

Indikator untuk menilai persepsi responden mengenai kondisi fisik hutan kota Serang meliputi aspek udara, aspek air, dan aspek ekologis, sedangkan untuk kondisi non fisik meliputi keamanan, kenyamanan, kelengkapan fasilitas, dan lain sebagainnya. Metode pengambilan sampel dilakukan secara incidental (incidental sampling) denga cara penyebaran kuesioner kepada 100 responden menggunakan skala likert.

\section{Analisis Statistik}

Dalam penelitian ini uji validitas menggunakan SPSS 25 dengan uji Pearson. Kriteria keputusan dari uji Pearson adalah jika sig. $(2$-tailed) $<0,05=$ valid dan jika sig. (2tailed) $>0,05=$ tidak valid [5]. Hasil pengolahan data dari SPSS, dari semua pernyataan yang terdapat dalam kuesioner dinyatakan valid. Uji reliabilitas dilakukan dengan teknik Alpha Cronbach. Secara umum suatu instrumen dikatakan reliabel jika koefisien Cronbach Alpha $>$ dari $r_{\text {tabel. Nilai }}$ $r_{\text {tabel }}$ sebesar 0,207 dengan nilai signifikansi $5 \%$. Hasil pengujian menunjukkan bahwa kuesioner penelitian untuk masing-masing 
indikator adalah reliabel dengan nilai 0,729 untuk aspek fisik dan 0,830 untuk aspek nonfisik.

Analisis data nilai ekonomi total (NET) merupakan penjumlahan dari nilai guna langsung, nilai guna tidak langsung, dan nilai bukan guna [6]. Penelitian ini dilakukan menggunakan metode survei melalui teknik valuasi ekonomi diantaranya:

Tabel 1. Teknik Penilaian Valuasi Ekonomi

\begin{tabular}{lll}
\hline \multicolumn{3}{c}{ Nilai Ekonomi Hutan Kota } \\
\hline A & Nilai Guna Langsung & \\
1 & Kayu & Harga Pasar, Harga Kayu \\
\hline B & Nilai Guna Tidak Langsung \\
1 & Resapan air & Biaya pengganti, nilai pasar untuk banyaknya air yang ditampung oleh sungai \\
2 & Serapan Karbon & Biaya produksi, biaya yang dikeluarkan atas nilai pasar karbon yang dapat diserap \\
\hline C & Nilai Pilihan & \\
1 & Rekreasi & Biaya rekreasi, biaya yang dikeluarkan untuk berkunjung di hutan kota \\
\hline D & Nilai Keberadaan & Kesediaan membayar (Willingness to Pay)
\end{tabular}

Sumber: Nur Raly [6]

\section{HASIL DAN PEMBAHASAN}

\section{Nilai Ekonomi Pohon}

Nilai ekonomi pohon dihitung dengan konsep harga pasar yaitu perkalian jumlah komoditas dengan harga komoditas [6]. Hasil inventarisasi hutan kota dengan luas 1,4 hektar jumlah pohon terdapat 576 pohon kayu dan 25 pohon palem [7]. Penentuan harga palem dengan survei penjual, dimana pohon palem dengan tinggi $2 \mathrm{~m}$ dipatok dengan harga Rp.7.000.000,00. Harga pohon kayu ditentukan berdasarkan Peraturan Menteri Kehutanan RI No. P.68/Menhut-II/2014, bahwa harga kayu rimba dengan diameter $<20 \mathrm{~cm}$ dipatok Rp.130.000,00/m³. Jadi nilai ekonomi total kayu hutan kota Serang adalah Rp.176.470.267,00 per hektar. Nilai kayu merupakan nilai produktivitas yang dimiliki oleh hutan kota Serang, nilai ini menjadi potensi asset bagi pemerintah daerah kota Serang dan akan terus berkembang jika bisa dikelola dengan baik.
Nilai ekonomi pohon ini tidak disadari oleh pemerintah maupun masyarakat, terlihat dari setiap program penghijauan yang akan dilaksanakan tidak dibuatkan perencanaan terlebih dahulu, sehingga pemangkasan pohon dilakukan secara sembarangan tidak melihat umur dan jenis pohon.

Tabel 2. Nilai Ekonomi Pohon

\begin{tabular}{|c|c|c|c|}
\hline Jenis Pohon & Jumlah & Harga (Rp) & Nilai Ekonomi (Rp) \\
\hline Palem & 25 Batang & 7.000 .000 & 175.000 .000 \\
\hline Pohon Kayu & $\begin{array}{l}11,30976 \\
\mathrm{~m}^{3}\end{array}$ & 130.000 & 1.470 .269 \\
\hline & Total & & $\begin{array}{l}\text { 176.470.267- } \\
\text { /hektar }\end{array}$ \\
\hline
\end{tabular}

\section{Nilai Ekonomi Resapan Air}

Hutan kota memiliki fungsi penyerapan air yang tinggi, diakibatkan oleh adanya proses infiltrasi yang dilakukan pepohonan yang terdapat didalam area hutan kota. Pernyataan ini telah didukung oleh hasil penelitian yang menunjukkan bahwa akumulasi air infiltrasi jauh lebih banyak dijumpai pada lahan dengan tanaman hutan (Eucalyptus sp, 
Pinus merkusii, dan Maesopsis sp) dari pada lahan dengan tanaman semusim dan tamanan bawah (Eupatorium sp) [8]. Hasil penelitian ini menegaskan kawasan hutan mempunyai fungsi lebih baik dalam mengatur tata air dari pada kawasan yang tidak berhutan seperti kawasan pertanian dan kawasan permukiman [9].

Nilai ekonomi resapan air hutan kota Serang dihitung berdasarkan kemampuan pohon untuk dapat menahan air. Hal ini diasumsikan bahwa satu pohon usia 10 tahun dapat menahan air kira-kira $7 \mathrm{~m}^{3}$ setara dengan $5 \mathrm{~m}^{3}$ kayu. Pohon-pohon yang ada di hutan kota rata-rata sudah berumur lebih dari 10 tahun [10]. Hasil perhitungan diperoleh bahwa dengan luas hutan kota 1,4 hektar terdapat 576 pohon dengan nilai potensi penyerapan air sebesar $4.032 \mathrm{~m}^{3}$.

Nilai ekonomi resapan air hutan kota Serang diperoleh dari besarnya biaya yang dikeluarkan oleh penduduk atas pemakaian air tanah yaitu Rp.4.512,00 / $\mathrm{m}^{3}$ harga air baku, sehingga di peroleh angka untuk nilai harga dasar air (HDA) sebesar Rp.125.434,00 sehingga nilai ekonomi resapan air hutan kota Serang sebesar Rp.505.749.888,00 pertahun. Hasil valuasi ekonomi dari resapan air diatas merupakan kemampuan hutan kota serang dalam menginfiltrasi air tanah.

Nilai ekonomi resapan air

$$
\begin{aligned}
& =\text { Rp. } 125.434,00 \times 4.032 \mathrm{~m} \\
& =\text { Rp. 505.749.888,00/tahun }
\end{aligned}
$$

\section{Nilai Ekonomi Serapan Karbon}

Salah satu fungsi dari keberadaan hutan kota adalah penyerapan karbondioksida dan penghasil oksigen yang sangat penting bagi kehidupan manusia. Semakin banyak jumlah dan jenis pohon yang terdapat didalam hutan kota Serang, maka kualitas penyerapan karbonpun akan semakin bagus. Penentuan nilai ekonomi serapan karbon untuk hutan kota Serang yaitu dilakukkan dengan cara pengukuran pohon pada tegakan tingkat pancang dan tiang dengan diameter $5-\geq 20$ $\mathrm{cm}$ dan tingkat pohon dengan diameter $\geq 20$ $\mathrm{cm}$ [1 1]. Total karbon yang tersimpan dengan menggunakan asumsi bahwa kandungan karbon kira-kira 50\% dari biomassa [12].

Hasil perhitungan jumlah pohon di hutan kota Kota Serang, terdapat 576 pohon dengan rata-rata memiliki tinggi di atas $10 \mathrm{~m}$ dan diameter $5 \mathrm{~cm}$, dengan jumlah biomasa sebesar $710.415,93 \mathrm{~kg} / \mathrm{m}^{2}$ dan jumlah karbon sebesar $355.207,47 \mathrm{~kg} / \mathrm{m}^{2}$ [1]. Maka potensi nilai ekonomi serapan karbon dari hutan kota tersebut sebesar Rp.4.972.400,00 ton/tahun.

\section{Nilai Ekonomi Rekreasi (Travel Cost Method)}

Nilai ekonomi rekreasi berdasarkan metode biaya perjalanan wisata (Travel Cost Method) digunakan untuk memprediksi besar kecilnya tingkat pengunjung ke hutan kota pada tahun tertentu, yang meliputi biaya transportasi pulang pergi dari tempat tinggalnya ke hutan kota Serang dan pengeluaran lain selama di perjalanan dan di dalam (biaya konsumsi, biaya dokumentasi, dan biaya lain-lain). Asumsi jumlah pengunjung hutan kota setiap tahun adalah 44.236 orang [1]. Maka perhitungan nilai ekonomi biaya rekreasi (Travel Cost Method) adalah: 


$$
\begin{gathered}
\text { Rata }- \text { rata biaya rekreasi }=\text { Rp. } \frac{2 \cdot 676.000,00}{100 \text { orang }} \\
=\text { Rp. } 26.760,00 / \text { orang } \\
\text { /kunjungan }
\end{gathered}
$$

Nilai ekonomi biaya rekreasi

$$
\begin{aligned}
& =\text { Rp. } 26 \cdot 760,00 \times 44.236 \text { orang } \\
& =\text { Rp. } 1 \cdot 180 \cdot 755 \cdot 360,00
\end{aligned}
$$

\section{Nilai Ekonomi Kesediaan Membayar}

Willingness to Pay (WTP) atau kesediaan untuk membayar adalah jumlah maksimum yang mau dibayar oleh konsumen untuk memperoleh suatu barang, dan sekaligus menjadi ukuran seberapa besar pembeli menilai suatu barang [13]. Perhitungan estimasi nilai WTP sebagai berikut :

Nilai ekonomi WTP $=\frac{\text { Rp. } 370.000,00}{100 \text { orang }}$

$$
=\text { Rp. 37.000,00 }
$$

Nilai kesediaan membayar (WTP)

$=$ Rp. 37.000,00 x 44.236 orang

$=$ Rp. 1.636.732.000,00

Nilai WTP pengunjung terbanyak adalah kelas Rp.9.000,00 sampai Rp.15.000,00 Hasil pengolahan nilai WTP pengunjung hutan kota Serang bahwa rata-rata niilai WTP pengunjung sebesar Rp.37.000,00. Maka nilai ekonomi warisan Hutan kota Serang adalah Rp.1.636.732.000,00.

\section{Nilai Ekonomi Keberadaan}

Nilai keberadaan hutan kota Serang merupakan nilai yang dimiliki oleh hutan kota Searng baik saat ini maupun masa yang akan datang. Keberadaan jenis dan jumlah pohon yang banyak di dalam hutan kota Serang, secara signifikan akan meningkatkan kenyamanan, dan keindahan kota Serang.

Hutan kota Serang dioperasikan sebagai ruang terbuka hijau yang memiliki nilai keindahan, kenyamanan, dan keharmonisan ekosistem hutan dengan manusia. Nilai ekonomi keberadaan dihitung dengan konsep WTP kesediaan membayar pengunjung yang merasakan langsung keberadaan hutan kota Serang [4]. Skenario pertanyaan yang digunakan hutan kota, berapakah tarif masuk yang bersedia dikeluarkan untuk mengunjungi hutan kota Serang? Perhitungan nilai WTP adalah sebagai berikut :

Rata - rata (mean)nilai WTP

$$
\begin{aligned}
& =\operatorname{Rp} \cdot \frac{322 \cdot 000,00}{100} \text { orang } \\
& =\text { Rp. } 3 \cdot 220,00
\end{aligned}
$$

Hasil wawancara pengunjung nilai WTP terbanyak adalah kelas Rp. $2.000,00$ sampai Rp.8.000,00 Selama satu tahun didapatkan nilai ekonomi keberadaan kawasan ini sebesar Rp.142.439.920,00.

\section{Nilai Ekonomi Total}

Nilai ekonomi total hutan kota Serang merupakan jumlah dari nilai guna, nilai guna tidak langsung, dan nilai bukan guna ${ }^{[4]}$. Berdasarkan hasil perhitungan terhadap seluruh nilai ekonomi hutan kota Serang didapatkan nilai :

$$
\begin{aligned}
\text { TEV }=\text { Rp. } 176.470 .267,00+\text { Rp. } 510.720 .675,00 \\
+ \\
+ \text { Rp. } 1.180 .755 .360,00 \\
+ \text { Rp. } 1.636 .732 .00,00 \\
\\
=\text { Rp. } 142.439 .920 .118 .222,00
\end{aligned}
$$


Dari hasil perhitungan diatas memberikan gambaran bahwa hilangnya hutan kota Serang secara otomatis akan menghilangkan manfaat nilai ekonomi baik nilai ekonomi resapan air, nilai ekonomi serapan karbon, nilai ekonomi rekreasi. Hal ini memperlihatkan bahwa hutan kota Serang memiliki nilai manfaat yang sangat tinggi baik saat ini maupun masa yang akan datang.

\section{Persepsi Mengenai Kondisi Fisik dan Non-Fisik}

\section{Hutan Kota Serang}

Kondisi fisik dan non-fisik menjadi salah satu hal penting dalam pengelolaan hutan kota Serang. Hasil wawancara respoden mengenai kondisi fisik hutan kota Serang, responden berpendapat bahwa hutan kota yang di butuhkan di Kota Serang adalah taman kota berupa pohon-pohon yang rindang dan hijau sehingga dapat memberikan kesejukan dan kenyamanan bagi masyarakat kota. Hal ini terkait dengan keindahan Kota Serang yang kurang baik akibat banyaknya pencemaran yang terjadi seperti pencemaran debu dan tingkat kebisingan yang tinggi.

Tingkat pemahaman masyarakat Kota Serang dapat dipengaruhi oleh pengetahuan yang didapatkan dari berita dan informasi yang berhubungan dengan hal-hal mengenai hutan kota. Selain itu, faktor pendidikan juga dapat mempengaruhi tingkat persepsi seseorang. Hal ini terlihat pada hasil persepsi masyarakat terhadap kenyamanan hutan kota saat ini hanya sebesar $35 \%$ sedangkan sebanyak $65 \%$ merasakan tidak nyaman.
Tingkat

persepsi

tersebut menggambarkan bahwa masyarakat sudah memahami tentang aspek pengenalan hutan kota yang dipengaruhi oleh banyaknya informasi mengenai hal-hal terkait dengan hutan kota. Sebagai sarana publik, responden hutan kota Serang kurang setuju dengan keamanan, kebersihan, pelayanan petugas, dan kelengkapan fasilitas yang tersedia di hutan kota Serang. Maka, Pemerintah perlu mengadakan program untuk meningkatkan kualitas hutan kota sehingga fungsi hutan kota dalam memberikan pelayanan terhadap lingkungan dapat berjalan secara optimal dan Pemerintah bersinergi dengan pihak swasta dalam pengelolaan hutan kota agar pelaksanaanya dapat berjalan sesuai dengan fungsi dan kewenangannya masing-masing.

\section{KESIMPULAN}

1. Nilai Ekonomi Total Hutan Kota Serang per tahun sebesar Rp.3.650.118.222,00, sehingga nilai potensi ekonomi dari hutan kota mencerminkan besarnya harga yang terkandung dari manfaat yang dimiliki oleh hutan kota Serang, dan memperlihatkan bahwa hilangnya hutan kota akan menghilangkan manfaat ekonomi bagi masyarakat sebesar angka tersebut.

2. Pengolahan data persepsi masyarakat, pengunjung hutan kota Serang kurang setuju sebesar $65 \%$ sedangkan $35 \%$ setuju bahwa kawasan ini memiliki kondisi fisik dan non-fisik yang baik. Secara kondisi fisik dan non-fisik hutan kota Serang tergolong cukup rendah. 


\section{SARAN}

Perlu adanya koordinasi dan sosialisasi yang intensif oleh pemerintah mengenai pemahaman ekosistem hutan kota Serang sehingga fungsi dan manfaat keberadaannya bisa dirasakan oleh masyarakat luas khususnya kota Serang. Pemerintah juga perlu meningkatkan pengelolaan terhadap hutan kota agar tercipta sumber daya yang berkelanjutan yang dihasilkan dari hutan kota Serang.

\section{REFERENSI}

[1] A. Masyruroh, Model Hutan Kota Dalam Upaya Perlindungan Lingkungan Hidup Yang Berkelanjutan (Kasus Kota Serang). Disertasi: Program Pasca Sarjana Universitas Indonesia. Jakarta. Tidak diterbitkan. 2019.

[2] Badan Perencanaan Pembangunan Daerah Kota Serang. (2015). Pendataan Pembangunan Industri 2013 dan 2014. Pembangunan Perumahan 2015. Kota Serang: Badan Perencanaan Pembangunan Daerah.

[3] Grey, G.W. \& Deneke, F.I. Urban Forestry. John Wiley and Sons. Inc. New York, 1978.

[4] Soemarno, Metode Valuasi Ekonomi sumberdaya Lahan Pertanian: Baha Kajian untuk MK Ekonomi Sumberdaya Alam. PDIP PPS FPUB, 2010.

[5] Sugiyono. Metode Penelitian Kuantitatif, Kualitatif, dan R\&D. Bandung : Alfabeta, 2017.
[6] Anjani, N. R., \& Harini, R.. Valuasi Ekonomi Hutan Kota Tebet Jakarta Selatan di DKI Jakarta. Jurnal Bumi Indonesia, 5(1), 2016.

[7] Dinas Pertamanan dan Pemakaman Kota Serang tahun, 2018.

[8] Millya, Y. Effa. Penilaian Ekonomi Hutan Kota (Studi kasus : Hutan Kota Srengseng, Jakarta Barat). Tesis Program Pasca Sarjana Universtas Indonesia, Tidak Diterbitkan, 2008.

[9] Hamdani. Pengaruh Konservasi Hutan Kota dan Hutan Sekunder sekitarnya Terhadap Lingkungan Fisik dan Sosial di Kota Tanjung Selor, Tesis: Program Pasca Sarjana Universitas Gajahmada, Yogyakarta, tidak Diterbitkan. 2001.

[10] Kodoatie, R. J. \& Sjarief, R.. Pengelolaan Bencana Terpadu. Jakarta: Yarsif Watampone, 2006.

[11] Badan Standardisasi Nasional Indonesia. Pengukuran dan penghitungan cadangan karbon - Pengukuran lapangan untuk penaksiran cadangan karbon hutan (ground based forest carbon accounting) Nomor 7724:2011. Jakarta: Badan Standardisasi Indonesia, 2011.

[12] Brown, S., \& Lugo, A.E.. Biomass of Tropical Forest: A New Estimate Based on Forest. Journal of Science. Vol. 223 : 1290-1293, 1984.

[13] Mankiw N,Gregory, dkk., Pengantar Ekonomi Makro. Jakarta: Salemba Empat, 2012. 